\title{
Phylogeography and population genetics of a widespread cold-adapted ant, Prenolepis imparis
}

\author{
Maria Tonione ${ }^{1}, \mathrm{Ke} \mathrm{Bi}^{2}$, Rob Dunn ${ }^{3}$, Andrea Lucky ${ }^{4}$, and Neil Tsutsui ${ }^{5}$ \\ ${ }^{1} \mathrm{UC}$ Berkeley \\ ${ }^{2}$ University of California Berkeley \\ ${ }^{3}$ North Carolina State University \\ ${ }^{4}$ University of Florida \\ ${ }^{5}$ University of California, Berkeley
}

November 29, 2021

\begin{abstract}
Historical climate fluctuations have left genetic signatures on species and populations across North America. Here, we used phylogenetic and population genetic analyses from 1,402 orthologous sequences of 75 individuals obtained through sequencing of Ultraconserved Elements (UCEs) to identify population genetic structure and historical demographic patterns across the range of a widespread, cold-adapted ant, the winter ant, Prenolepis imparis. We relate the genomic patterns to those expected as a result of in situ diversification, maintained connectivity, or recent migration. We recovered five well-supported, genetically isolated clades across the distribution: 1) a basal lineage located in Florida, 2) populations across the southern United States, 3) populations that span the midwestern and northeastern United States, 4) populations from the western United States, and 5) populations in southwestern Arizona and Mexico. Using Bayesian clustering analysis in STRUCTURE and k-means clustering in ADEGENET, we investigated gene flow between these major genetic clades and did not find evidence of gene flow between clades. We did find evidence of localized structure with migration in the western United States clade. High support for five major geographic lineages and lack of evidence of contemporary gene flow indicate in situ diversification across the species' range, probably influenced by glacial cycles of the late Quaternary.
\end{abstract}

\section{Hosted file}

2021_1108_Prenolepis_Phylogeography.docx available at https://authorea.com/users/448500/ articles/547300-phylogeography-and-population-genetics-of-a-widespread-cold-adapted-antprenolepis-imparis 